\title{
Morcegos como tema gerador para o ensino de ciências e educação ambiental nas escolas de ensino básico: uma abordagem cienciométrica
}

\author{
Bats as a generating theme for the teaching of science and \\ environmental education in primary schools: a scientific approach
}

\author{
1 Andrew Vinícius Cristaldo da Silva andrew.biologia@yahoo.com.br \\ 1 Valdênia Rodrigues Fernandes Eleotério \\ 2 Fátima Cristina Duarte Ferreira Cunha
}

Universidade Católica Dom Bosco
Universidade Federal de Mato Grosso do Sul

\section{Resumo}

O presente artigo buscar realizar um levantamento e uma caracterização de artigos relacionados a práticas de educação ambiental e ensino de ciências para conservação de morcegos, por meio de levantamento cienciométrico utilizando as bases de dados. Os trabalhos foram categorizados quanto ao ano de publicação, a localização e o direcionamento do estudo, agrupados e analisados. Os resultados permitem concluir que pesquisas relacionadas aos morcegos, como tema gerador de práticas de Educação Ambiental (EA) e Ensino de Ciências (EC) nas escolas de ensino básico são escassas e que a divulgação científica favorece aqueles que creem que ainda é válido transformar o ensino.

\section{Palavras-chave}

Cienciometria. Desmistificação. Educação científıca.

\begin{abstract}
The present article seeks to carry out a survey and a characterization of articles related to environmental education practices and teaching of sciences for the conservation of bats, by means of a scientometric survey using the databases. The studies were categorized according to the year of publication, location and direction of the study, grouped and analyzed. The results allow us to conclude that research related to bats, as a theme generating practices of Environmental Education and Science Teaching (EC) in primary schools are scarce and that scientific dissemination favors those who believe that it is still valid to transform teaching.
\end{abstract}

\section{Keywords}

Scientiometry. Demystification. Scientific Education.

\section{Como você deve citar?}

SILVA, Andrew Vinícius Cristaldo da; ELEOTÉRIO, Valdênia Rodrigues Fernandes; CUNHA, Fátima Cristina Duarte Ferreira. Morcegos como tema gerador para o ensino de ciências e educação ambiental nas escolas de ensino básico: uma abordagem cienciométrica. Cadernos UniFOA, Volta Redonda, n. 42, p. 125-130, abril, 2020. 
Morcegos como tema gerador para o ensino de ciências e educação ambiental nas escolas de ensino básico: uma abordagem cienciométrica

\section{INTRODUÇÃO}

O Ensino de Ciências, desde a década de 1980, vem proporcionando um campo produtivo para discussões acerca de questões ambientais, dado que as preocupações da sociedade com o meio ambiente acentuaram nas últimas décadas. A escola possui papel fundamental na divulgação do conhecimento científico, no entanto, nem ela nem nenhuma instituição consegue acompanhar a evolução das informações científicas, necessárias à compreensão do mundo (OLIVEIRA, 2006).

Concomitante aos avanços nos campos de publicações, pesquisas e procedimentos científicos, uma vertente metodológica avança em ritmo bastante acelerado (KLUMPP et al., 2001). A Cienciometria congrega informações oriundas de diversas esferas do saber humano e objetiva, mediante a produção de indicadores quantitativos, instrumentalizar a divulgação de informações (MUGNAINI et al., 2004). Sendo assim, as técnicas cienciométricas são importantes para identificar o desenvolvimento do conhecimento (SPINAK, 1998).

Tópico importante dentro da EA e EC é a conservação dos morcegos, devido a sua importância na manutenção da qualidade ambiental, visto que possuem hábitos alimentares diversificados (KUNZ e FENTON, 2003). Ademais, essa conservação mantém funções no ambiente, atuando como controladores de insetos, polinizadores de plantas e dispersores de semente (KUNZ et al., 2011), importantes na regeneração de ecossistemas florestais (MEDELLíN e GAONA, 1999). Os morcegos (ordem Chiroptera) abrangem mais de 1.300 espécies reconhecidas (FENTON; SIMMONS, 2015), total que engloba quase um quinto das espécies de mamíferos do mundo (SIMON et. al, 2011).

Apesar dos benefícios para a sociedade, Scavroni et al. (2008) afirmam que, dentre os grupos de mamíferos, os morcegos são os mais envolvidos com a desinformação das pessoas. Isso pode ser justificado, visto que eles apresentam características peculiares, como o hábito noturno e a ocorrência de representantes hematófagos, fatos que podem contribuir para que a sociedade os veja como animais perigosos, associados à morte e a espíritos malignos, além das falsas imagens atribuídas por meio de filmes e superstições, embutidos na mente do público, impedindo a aceitação desses animais (KINGSTON et. al, 2006).

Tendo em vista o grande potencial que os morcegos exercem no ambiente e a falta de conhecimentos sobre eles pela sociedade, o objetivo do presente estudo foi realizar um levantamento cienciométrico sobre estudos relacionados a práticas de Educação Ambiental e divulgação científica relacionadas aos morcegos, considerando que a escola serve de princípio para a construção do conhecimento.

\section{METODOLOGIA}

A revisão dos artigos científicos que abordaram as pesquisas foi realizada, com base nos artigos indexados pela base de dados Thomson Reuters, SciVerse Scopus, Periódico CAPES e a Revista Enseñanza de las Ciências, respectivamente, com a finalidade de obter um maior número de artigos científicos. O levantamento dentro dessas bases de dados foi realizado de fevereiro a dezembro de 2015, utilizando-se as palavras-chave "Bats", "Chiroptera", "Enviromnental Education", "School", "Students", "Education". Essas palavras foram utilizadas em grupos de três, em várias ordens. As palavras "Bats", "Chiroptera" sempre eram empregadas. Os artigos que apresentaram ocorrência nas três bases de pesquisas e na revista foram considerados apenas uma vez. Vale ressaltar que essas bases de dados funcionam como bibliotecas eletrônicas que abrangem os periódicos indexados considerados de maior qualidade científica. 
As classificações foram realizadas mediante a leitura do artigo completo que foram categorizados quanto ao ano de publicação, a localização (levando em consideração o continente) e o direcionamento do estudo (para alunos ou professores).

Os anos de publicação foram agrupados em intervalos de dois anos, iniciando-se a partir de 1999 (primeiro ano de registro) com término em dezembro de 2015, para uma maior confluência frente à apresentação dos dados, exceto os três últimos anos, que foram agrupados em uma categoria. Assim, foram obtidos oito intervalos de tempo: 1999-2000, 2001-2002, 2003-2004, 2005-2006, 2007-2008, 2009-2010, 2011-2012, 2013- 2014- 2015. Para cada uma das classificações, os dados foram agrupados e analisados pelo software StatSoft Statistica.

Foram selecionados 79 artigos. Todos os artigos retratavam sobre educação ambiental e/ou ensino de ciências relacionados obrigatoriamente aos morcegos, na educação básica. Aqueles que não atendiam ao objetivo do presente estudo foram desconsiderados e os que apresentaram equivalência nas bases de pesquisas e na revista foram considerados apenas uma vez. Com isso, foram utilizados para análise cienciométrica 36 artigos científicos.

\section{RESULTADOS E DISCUSSÃO}

Os quatro primeiros intervalos de tempo registraram a menor quantidade de artigos publicados $(n=3, n=1, n=3, n=2$, respectivamente). 0 período em que ocorreu uma maior produção científica foi entre 2011-2012 ( $n=11)$ (Figura 1). Entretanto, as publicações acerca da temática ainda são escassas. Amin \& Mabe (2000) afırmam que, se não há veiculação de informação suficiente acerca de um tema, há, portanto, o desconhecimento sobre o assunto pela população.

Figura 1- Número de artigos em EA e EC sobre morcegos em anos

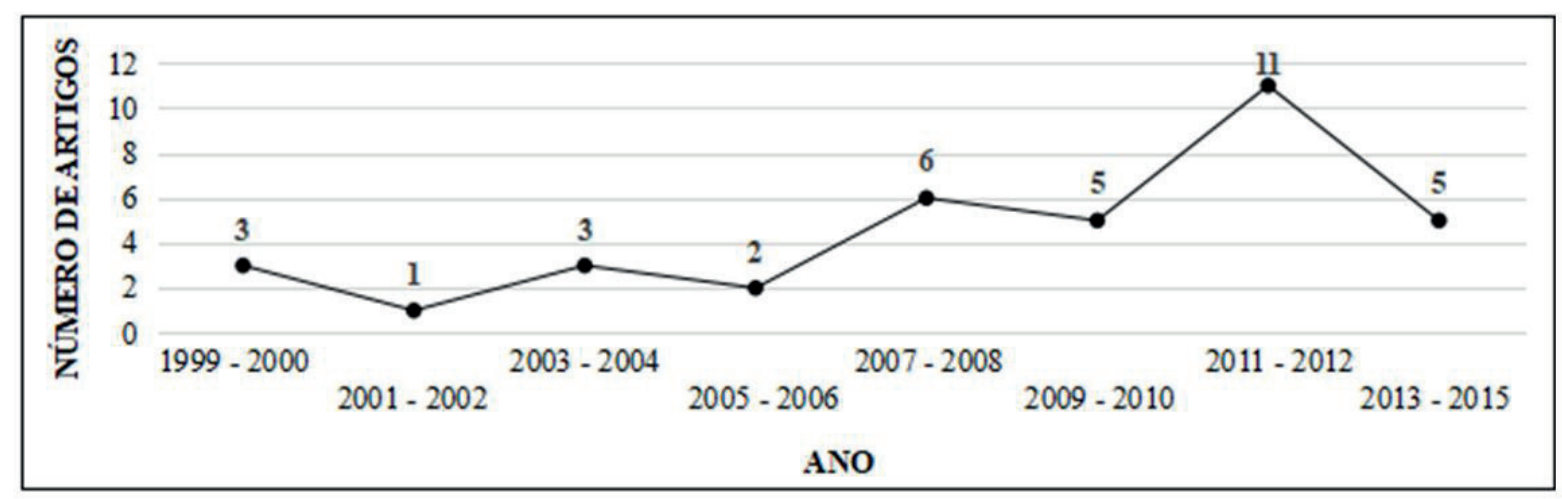

Fonte: Amin; Mable, 2000.

Sato (2000) relata que há uma urgência em gerenciar os problemas ambientais. Isso levou as diversas esferas institucionais a voltar suas atenções frente a esses problemas. Diante disso, as Nações Unidas e a EUROBATS (Acordo sobre a Conservação dos Morcegos na Europa) instituíram os anos de 2011 e 2012 como o ano do morcego. Essa campanha resultou de vários esforços internacionais, o que pretendeu promover a conservação, investigação e educação sobre os quirópteros.

Entretanto, voltar a atenção de cientistas e da população para campanhas a fim de haver conscientização ainda são ineficientes e precisam ser mais bem estruturadas, fato que pode ser observado com a redução do número de trabalhos relacionados aos morcegos após o biênio 2011-2012. Pelicioni 
Morcegos como tema gerador para o ensino de ciências e educação ambiental nas escolas de ensino básico: uma abordagem cienciométrica

(1998) afirma que a EA deve ser trabalhada de forma contínua e permanente. Loureiro (2004) reitera dizendo que a EA não pode enfatizar vertentes pragmáticas que exigem atitudes e práticas curtas, e que sempre deve haver continuidade, para que haja, assim, construção de conhecimentos.

Considerando a localização geográfica, os maiores esforços de pesquisas ocorreram na América do Norte (AN) (12 artigos), Europa $(n=8)$, América do Sul $(n=7)$, Ásia $(n=5)$ e América Central $(n=4)$. Não foram encontrados registros de publicações na África, Oceania e Antártida (Figura 2). Larsen (2010) aponta que os EUA, Europa e a Ásia possuem grande potencial para alavancar as pesquisas científicas no mundo, tendo em vista o grande investimento na área.

Figura 2 - Número de artigos de EA e EC sobre morcegos nos continentes

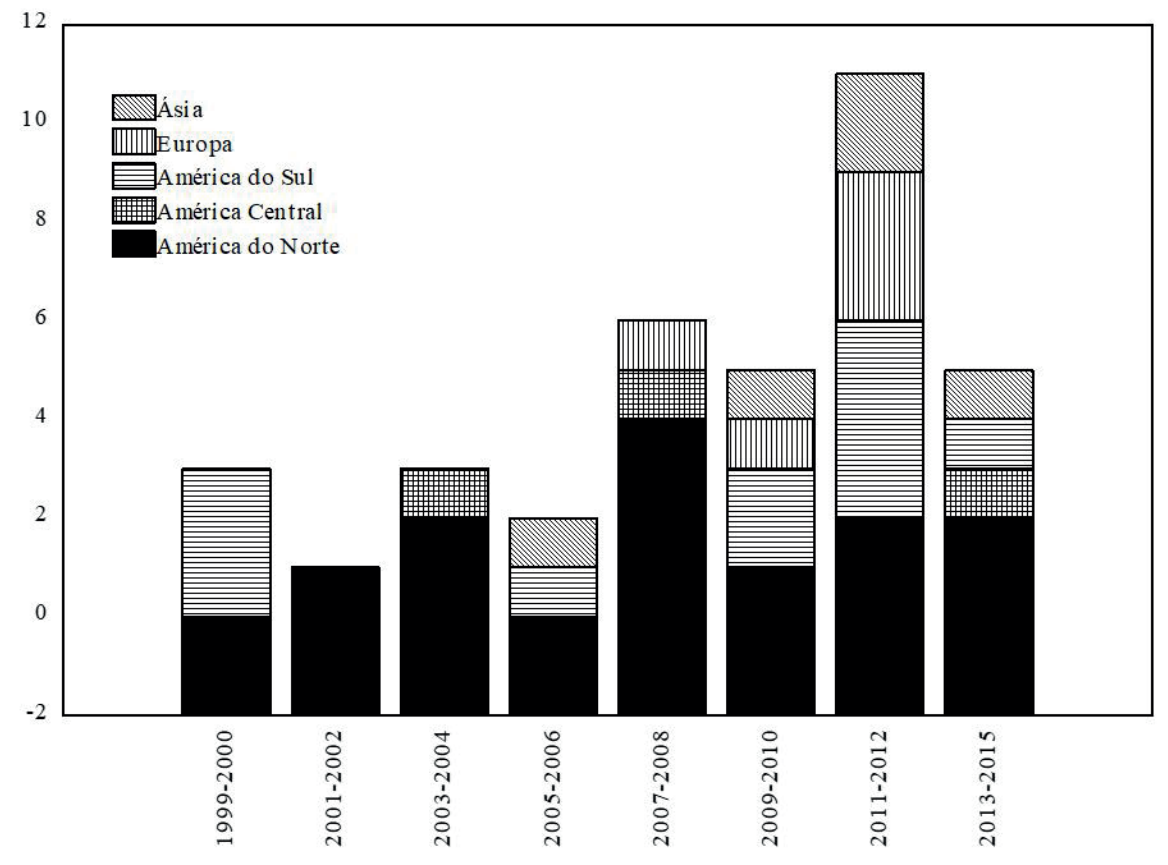

Fonte: Cristaldo da Silva (2016)

No Brasil, foram constatados dois trabalhos relacionados à EA e ao EC sobre morcegos nas escolas de ensino básico. D'Ambrózio (1999) ressalta que o Brasil precisa de programas que gerem avanço da ciência. A baixa produção científica no país se justifica, como levantado por Lima-Ribeiro et. al (2007) e Lolis et. al (2009), devido aos poucos incentivos à pesquisa, o que poderia ser resolvido com uma maior ação incentivadora, tanto por parte de órgãos governamentais, como no meio acadêmico-científico. Isso também pode estar associado à falta de pesquisadores, no meio acadêmico, que abordem o tema.

A maioria dos artigos analisados, $72,2 \%$ (26/36), apresentou um direcionamento do estudo para os alunos, enquanto o total de estudos voltados para os professores foi menor $(n=2)$. Em oito dos trabalhos, não foi possível distinguir o público-alvo, dado que somente retratam a ecologia do morcego na escola. Inserir e trabalhar sensibilização ambiental com alunos é fundamental para uma mudança de atitude sobre o mundo em que vivemos (SAUVE, 2005; SCRAVONI et. al, 2008).

No que se refere aos professores, há muito a ser feito, já que, muitas vezes, os educadores possuem concepções erradas sobre um determinado tema. Guimarães (2007) afırma que a deficiência na formação do professor é evidente, principalmente sobre questões relacionadas ao meio ambiente. Os professores entendem a importância, entretanto apontam essa necessidade somente para o aluno 
(FERREIRA, 2004). Mediante essas informações, bem como correlacionando com a falta de pesquisadores relacionados à EA para conservação de morcegos com os educadores, é evidente que haverá deficiência frente a esses assuntos.

\section{CONSIDERAÇÕES FINAIS}

O levantamento de artigos relacionados aos morcegos, como tema gerador de práticas de EA e EC nas escolas de ensino básico, evidenciou a escassez das pesquisas relacionadas ao tema, uma vez que foram encontrados poucos artigos, apesar da importância dos quirópteros para a manutenção da qualidade e integridade dos ecossistemas. Além disso, a educação científica e a ambiental são vistas de maneira antagônica e pragmática, as quais devem ter uma verdadeira reflexão frente aos interesses ambientais.

Caso as pesquisas voltadas para a EA, com a finalidade de desmistificar os morcegos e reiterar sua importância para a natureza ainda continuarem em escassas, a sociedade continuará relacionando os morcegos como animais do mal, terríveis e temíveis.

Sabe-se que a sensibilização e a conscientização da ciência para com o público está longe de ser alcançada. Todavia, ponderar sobre tais assuntos e divulgá-los, de certa forma, favorecem aqueles que creem que ainda é válido transformar o ensino.

\section{REFERÊNCIAS}

AMIN, M. \& B. MABE, 2000. Impact factors: use and abuse. Perspectives in Publishing 1: 1-6

D'AMBROSIO, U. Educação para uma sociedade em transição. Campinas: Editora Papirus, 1999.

FENTON M. B, SIMMONS N. B 2015. Bats, a world of science and mystery, The University of Chicago Press, Chicago, $303 \mathrm{pp}$

FERREIRA, A. R. Meio ambiente: representações e prática dos professores e professoras de ciências e biologia. 2004. 117f. Dissertação (Mestrado em Educação) - Universidade Estadual de Ponta Grossa, 2004.

GUIMARÃES, M. A formação de educadores ambientais. 3. ed. Ed. Papirus. Campinas, São Paulo, 2007.

KINGSTON, T. et. al. The Malaysian Bat Conservation Research Unit: Research, capacity building and education in an Old World hotspot. Proceedings of the National Seminar on Protected Areas. Kuala Lampur, Malaysia Department of Wildlife and National Parks. 2006.

KLUMPP, A.; ANSEL, W.; KLUMPP, G. \& A. FOMIN. 2001. Um novo conceito de monitoramento e comunicação ambiental: a rede europeia para a avaliação da qualidade do ar usando plantas bioindicadores, EuroBionet. Ver. Brás. Bot., n.4. supl., 511-518.

KUNZ, T.H.; FENTON, M. B. 2003. Bat Ecology. The University of Chicago Press, Chicago. 779p.

LARSEN, P. O., \& Ins, M. (2010). The rate of growth in scientific publication and the decline in coverage provided by Science Citation Index. Scientometrics, 84(3), 575-603. 
Morcegos como tema gerador para o ensino de ciências e educação ambiental nas escolas de ensino básico: uma abordagem cienciométrica

LIMA-RIBEIRO, M. S. et al. Análise cienciométrica em ecologia de populações: importância e tendência dos últimos 60 anos. Acta Sci. Biol. Sci., Maringá, v.29, n. 1, p.39-47, 2007.

LOLIS, S. F., SANCHES-MARQUES, A. M. M., ARRUDA REIS, S. R., BENEDITO, E. Scientometric analysis of energetic ecology: primary production of aquatic macrophytes. Acta Scientiarum. Biological Sciences, v. 31, n. 4, p. 363-369, 2009.

LOUREIRO, C. F. B. Trajetória e fundamentos da educação ambiental. São Paulo: Cortez, 2004

MEDELLIN, R. A. \& GAONA, O. 1999. Seed dispersal bats and birds in forests and disturbed habitats of Chiapas, Mexico. Biotropica, 31:478-485.

MUGNAINI, R; JANNUZZI, P; QUONIAM, L. Indicadores bibliométricos da produção científica brasileira: uma análise a partir da base de Pascal. Ci. Inf. Brasília, v. 33, n. 2, p 128-131, maio/ago. 2004

OLIVEIRA, A. L. Educação Ambiental: concepções e práticas de professores de ciências do ensino fundamental. 2006. Dissertação (Mestrado). Universidade Estadual de Maringá. Maringá - PR, 2006.

PELICIONI, M. C. F. Educação Ambiental, qualidade de vida e sustentabilidade. Saúde e Sociedade. São Paulo. p. 19-31, 1998.

SATO, M. Formação em educação ambiental: da escola à comunidade. In: Panorama da Educação Ambiental no Brasil. Brasília: MEC, março de 2000, 5-13.

SAUVÉ, L. Para construir un patrimonio da investigación em educación ambiental. Tópicos em Educación Ambiental, La Rioja, v. 2, n. 5, p. 51-69, 2005.

SIMON R, HOLDERIED MW, Koch CU, von Helversen O 2011. Floral acoustics: conspicuous echoes of a dish-shaped leaf attract bat pollinators. Science 333: 631-633.

SCAVRONI, J.; P., L. M. e U. W. 2008. Morcegos: realidade e fantasia na concepção de estudantes das áreas rural e urbana de Botucatu, SP. Revista Simbio-Logias. V. 1, n.2 Instituto de Biociências, Depto. Educação, UNESP, São Paulo, 2000. p.1-145.

SPINAK, E. Indicadores cienciometricos, Brasília, Ciência da Informação, v. 27, n. 2, p. 141-148, maio/ago 1998. 